\section{LITERATURA Y CINE EN LA VANGUARDIA FRANCESA: UNA ARQUEOLOGÍA VISUAL}

\author{
Antonio Ansón \\ Universidad de Zaragoza \\ aanson@unizar.es
}

\section{LITERATURE AND FILM IN THE FRENCH AVANT-GARDE: A VISUAL ARCHAEOLOGY}

Cómo citar este artículo/Citation: Ansón, A. (2014). "Literatura y cine en la vanguardia francesa: una arqueología visual". Arbor, 190 (768): a159. doi: http://dx.doi.org/10.3989/ arbor.2014.768n4013

Recibido: 2 junio 2011. Aceptado: 25 marzo 2013

RESUMEN: En este trabajo llevamos a cabo una investigación sobre el modo en que el cine fue recibido e interpretado por los escritores e intelectuales de vanguardia afincados en $\mathrm{Pa}$ rís durante primera mitad del siglo XX. La investigación hace posible hacernos una idea de cómo se entendió el cine por sus primeros espectadores, tanto desde un punto de vista técnico como cultural.

PALABRAS CLAVE: Cine; literatura; recepción; vanguardias; Francia.

El cine -recordaba Léon Paul Fargue a mediados del siglo pasado- ha trastornado todo. Ha dislocado la civilización, la ha acariciado un instante, el tiempo de perderla, y después la ha atrapado en su ritmo [le cinéma a tout chambardé. II a disloqué la civilisation, I'a caressée un instant, le temps de la prendre, puis l'a attirée dans son rythme] (Fargue, 1944, p. 225). Ciertamente el cine supuso, y también con la fotografía, con la construcción de imágenes mecánicas sin la (aparente) intervención del hombre, la herramienta
Copyright: (c) 2014 CSIC. Este es un artículo de acceso abierto distribuido bajo los términos de la licencia Creative Commons Attribution-Non Commercial (by-nc) Spain 3.0.

ABSTRACT: This study looks at how cinema was received and interpreted by avant-garde writers in Paris during the first half of the 20th Century. The research helps us get an idea of how cinema was understood by its first audiences from both the technical cultural point of view.

KEYWORDS: Cinema; literature; avant-garde; France.

comunicativa de mayor impacto desde finales del siglo XIX, decisiva para entender el lenguaje de la modernidad. Para entender cómo tuvo lugar este impacto en el ámbito de la literatura y del arte y las condiciones en las que se desarrolló, tenemos que llevar a cabo hoy un trabajo de arqueología visual. La respuesta la encontramos en los testimonios y las expectativas que el cine generó entre los intelectuales que asistieron al nacimiento de séptimo arte como espectadores privilegiados. Por otra parte, al tiempo que el cine se ilu- 
mina ante los ojos deslumbrados de aquellos poetas y pintores existen ya las condiciones estéticas necesarias para comprender el nacimiento de la narración visual. El cine, en este sentido, es más el síntoma que la causa. El cine es, en cierto modo, la consecuencia.

El concepto de imagen, no tanto como representación icónica, sino recurso asociativo se constituye en un principio básico de producción de sentido. Esta fórmula expresiva basada en la asociación que se generaliza en el conjunto de las disciplinas artísticas, desarrolla recursos como la secuencialidad, la elipsis y otorga un protagonismo hasta ese momento inédito a los objetos en el dominio de la plástica y a los sustantivos en literatura, con su equivalente en el primer plano en términos cinematográficos. Para comprender la importancia de esa visualidad mecánica vamos a rastrear la experiencia cinematográfica de los primeros espectadores del séptimo arte. Esos testimonios de escritores y artistas plásticos se articula en torno a dos aspectos: por un lado revelan el aprendizaje de un lenguaje nuevo que les deslumbra, por otro lado, este descubrimiento tiene consecuencias estilísticas en su manera de hacer. Aprenden a ver cine al tiempo que el propio cine se inventa como lenguaje. Es un reto hoy imaginar lo que supuso el impacto de esta nueva retórica visual, y un desafío para el espectador contemporáneo prescindir de sus competencias visuales para emplazarse, ver y comprender desde la inocencia de unos ojos ávidos y deslumbrados.

Aceptamos como un lugar común la influencia del cine en las formas literarias. El cine, sin embargo, como concepto, encuentra sus raíces formales en la enunciación que Lautréamont hace de la belleza, casi medio siglo antes de que Griffith difundiera el cine moderno. Se trata de un recurso, como mostraremos a continuación, que constituye la base de la articulación del lenguaje moderno y que encuentra su eclosión en el cine. Con el cine sucede un fenómeno estético similar al descrito por Jonathan Crary para la fotografía en Techniques of the Observer. Los intelectuales quedan fascinados por lo que Ricciotto Canudo acuñó como séptimo arte, pero ya están preparados y formados desde un punto de vista estético para comprender el fenómeno cinematográfico en términos de recursos expresivos. Es decir, la imagen cinematográfica no es la causa sino el síntoma de los cambios que ya se habían producido y encuentran en el cine su expresión máxima. El cine, como vamos a comprobar a continuación, viene a materializar las transformaciones más importantes del siglo XX en la historia de las formas literarias, tanto en su estructura como en su estilo. Los argumentos que Jorge Urrutia encuentra en Jean Epstein para explicar la concordancia entre la discontinuidad del cine y la poesía, hay que reportarlos mucho antes y a argumentos literarios (Urrutia, 2002, p. 152). Del mismo modo, nos parece inexacta la aseveración de Rafael Utrera al afirmar que "fue el surrealismo quien revalorizó el poder de la imaginación y equiparó la belleza con la realidad" (Utrera Macías, 2006, p. 29). Con anterioridad el cubismo abandonó la realidad y su imitación para reivindicar el cuadro como un elemento que se sumara a la realidad misma, y con anterioridad y en términos similares los escritores conocidos como decadentes. En el último cuarto del siglo XIX se fraguan y asientan buena parte de los fundamentos que caracterizan las vanguardias históricas.

Hasta Lautréamont la expresión literaria y artística se estructura en torno a la figura como procedimiento. Lo que caracteriza a la figura literaria es la justificación formal e intelectual que pone en relación los elementos implicados en el proceso comunicativo, tanto por sustitución, como sucede la metáfora, por ejemplo, o por afinidad en el caso de la comparación. En la figura nos hallamos siempre ante un mecanismo que encuentra su sentido y se justifica desde sus contenidos. A finales del siglo XIX irrumpe un nuevo concepto que renuncia al vínculo de la sustitución que tiene lugar en la metáfora $(A=B)$ o la comparación (A es como B) para dar paso a la suma de dos elementos sin otra justificación que la suma $(A+B)$. Y de esa asociación surge, como dirá más tarde el poeta Pierre Reverdy, el chispazo de la poesía. El inventor de la imagen como concepto y el primero e formular su definición es Lautréamont en 1869 con su célebre Cantos de Maldoror. Allí define la belleza como "la rétractabilité des serres des oiseaux rapaces; ou encore, comme l'incertitude des mouvements musculaires dans les plaies des parties molles de la région cervicale postérieure ; ou plutôt, comme ce piège à rats perpétuel, toujours retendu par l'animal pris, qui peut prendre seul des rongeurs indéfiniment, et fonctionner même caché sous la paille; et surtout, comme la rencontre fortuite sur une table de dissection d'une machine à coudre et d'un parapluie" ["la retractilidad de las garras en las aves de rapiña; o, incluso, como la incertidumbre de los movimientos musculares en las llagas de las partes blandas de la región cervical posterior; o más bien, como esa ratonera perpetua, siempre tensa por el animal atrapado, que puede cazar por sí sola, indefinidamente, roedores y funcionar, incluso, oculta bajo la paja; y, sobre todo, como el encuentro fortuito de una máquina de coser y un paraguas en 
una mesa de disección"] (Lautréamont, 1953, p. 327), a la que Man Ray dará forma en su fotografía del mismo título en 1933.

Se trata de un recurso que va repetirse en la primera y la segunda vanguardia poéticas en el París de la primera mitad del siglo XX, y se hará extensible al conjunto de las artes. Reaparece en Arte poético de Max Jacob cuando escribe en 1915 que la nueva poesía está hecha de "conclusiones imprevistas" y "asociaciones de palabras e ideas" (Jacob, 1987, p. 16), y Pierre Reverdy retoma los postulados de Lautréamont en su definición de imagen poética aparecida en 1918 en su revista Nord-Sud:

L'image est une création pure de l'esprit.

Elle ne peut naître d'une comparaison mais du rapprochement de deux réalités plus ou moins éloignées.

Plus les rapports des deux réalités rapprochées seront lointains et justes, plus l'image sera forte, plus elle aura de puissance émotive et de réalité poétique.

[ La imagen es pura creación del entendimiento.

No puede nacer de una comparación sino de la aproximación de dos realidades más o menos alejadas.

Cuanto más alejada y certera sea la relación entre las dos realidades reunidas, más intensa será la imagen, más fuerza emotiva y realidad poética tendrá] (Reverdy, 1975, p. 73).

Se repite de forma literal en el segundo manifiesto surrealista de 1924, y subyace en el collage y en el fotomontaje como procedimiento de producción de sentido, como señalábamos más arriba. "Il est faux, selon moi, -escribe Breton- de prétendre que "I'esprit a saisi les rapports" de deux réalités en présence. II n'a, pour commencer, rien saisi consciemment. C'est du rapprochement en quelque sorte fortuit des deux termes qu'a jailli une lumière particulière, lumière de l'image" ["Es falso, en mi opinión, pretender que el pensamiento ha relacionado dos realidades juntas. Para empezar no ha asociado nada de forma consciente. Es por el acercamiento más o menos fortuito de dos términos de donde surge una luz particular, la luz de la imagen"] (Breton, 1985, pp. 48-49). Otro tanto puede decirse para el montaje cinematográfico en su concepción más mecánica, tal y como Eisenstein lo define en 1923 al describir su idea de "Montaje de atracción" (Eisenstein, 1986, pp. 181-183).

El concepto de imagen que se gesta en Lautréamont pone de manifiesto el gran descubrimiento que consiste en articular un significado mediante la asociación de dos elementos dispares y unidos sin otro vínculo que la suma es uno de los ejes constitutivos de la retórica comunicativa de la modernidad. El cine viene a poner de manifiesto y a desarrollar hasta sus últimas consecuencias ese procedimiento asociativo con resultados formales, como señalamos arriba, que se traducen en la elipsis, la secuencia y el valor sustantivo de los objetos que surgen con el primer plano.

Los intelectuales de la primera mitad del siglo XX, que confluyen en París, centro neurálgico de cuanto sucedía en el ámbito del arte occidental, demostraron muy pronto un gran interés por el nuevo medio que comenzaba a expandirse sin distinción de países o clases sociales. No sólo estos escritores se interesaron por el cine, sino que el arte en su conjunto descubrió y puso en práctica esos procedimientos visuales que las imágenes cinematográficas ofrecían.

Resulta difícil imaginar hoy la dificultad que aquellos primeros testigos para entender, por falta de competencia visual, la función narrativa de un primer plano, de consecuencias estéticas enormes. Tanto el deseo por comprender la técnica y los modos de expresión de esta herramienta para ellos desconocida, como un intercambio de influencias entre imágenes y palabra escrita, se manifiesta en una serie de testimonios que revelan una creciente preocupación por las cuestiones relacionadas con la imagen. Esos escritos nos informan sobre el modo en que artistas, escritores e intelectuales acogieron el cine, en la mayoría de los casos con entusiasmo, si bien no faltan las voces que expresan reticencias y recelos. En muchos casos la relación con el cine terminó para los primeros en una gran decepción, esperanzas depositadas en el cine y frustradas por el propio cine, que se alejó de propuestas experimentales para encontrar su lenguaje propio desde una estética naturalista.

Podemos distinguir dos grandes tendencias en lo concerniente a las reflexiones de los escritores del cine: la que descubre en las imágenes cambios retóricos importantes próximos a sus propias preocupaciones estilísticas, por lo que existirá, igualmente, un reflejo inmediato en las obras de creación, y otra, no menos importante, que analiza cuestiones literarias y cinematográficas desde la perspectiva del pensamiento y las transformaciones sociales que ello acarrea.

Estos escritos se agrupan, por tanto, en aquellos donde el autor lleva a cabo una reflexión en torno al cine que puede manifestarse bajo la forma del ensayo, de un comentario, digresiones o la sencilla reseña sobre un estreno, y por otro, obras concebidas desde 
la perspectiva exclusiva del cine, es decir, escritas a partir y como consecuencia del cine: paráfrasis poéticas a partir de motivos cinematográficos, imitaciones visuales, o la fórmula que más éxito tuvo en aquel momento bajo el apelativo de cinepoemas, poemas y dramas cinematográficos o cinenovelas. Muchos de estos textos tenían su origen en propuestas y proyectos de guiones cinematográficos nunca realizados, que eran reescritos y transformados en textos literarios de perfil e intenciones visuales.

Como apuntábamos más arriba, si bien la respuesta hacia el fenómeno cinematográfico por parte de escritores e intelectuales resulta en su conjunto rotun$\mathrm{da}$, por cuanto tiene de general y numerosa, no todos acudieron a la imagen de mismo modo y tampoco siempre de manera favorable. Tampoco la intensidad de sus intereses, ni el grado y la profundidad de compromiso con un medio que desde un primer momento inspiró grandes recelos es el mismo para todos ellos.

Existe, claro está, un grupo de escritores que acepta, defiende y asimila el vehículo de expresión del cine sin reticencias y de manera incondicional. Desarrollan una importante actividad teórica en torno a un fenómeno que les es extraño por cuanto tiene de desconocido. Sus análisis están dirigidos, precisamente, hacia la comprensión de un lenguaje en formación. Descubren en el cine un lenguaje exclusivo con reglas propias. Enseguida comprenden que se están enfrentando a un conjunto procedimientos novedosos que tratan de asimilar mediante el análisis de ese lenguaje todavía por descubrir. Pronto lo hacen propio y aplican esos mismos recursos en la creación literaria.

Entre esos autores destaca Ricciotto Canudo, uno de los primeros escritores del cine y teóricos de la imagen, adelantado en proclamar la revolución que el cinematógrafo trae a la literatura. Otros como Antonin Artaud, Jules Romains, Blaise Cendrars, Robert Desnos, Benjamin Fondane, Philippe Soupault, Benjmain Péret o Georges Ribemont-Dessaignes, son el reflejo de una importante actividad que condujo a la poesía francesa al encuentro teórico y práctico entre cine y literatura. Además de una reflexión analítica sobre aspectos lingüísticos, realizaron una cuantiosa producción de textos con un perfil radicalmente cinematográfico, además de guiones de cine y colaboraciones directas con productoras y directores.

Otro grupo significativo de poetas e intelectuales franceses, entre los que destacan Paul Morand, André Maurois, Georges Duhamel, Léon Paul-Fargue, André Salmon, Colette, Pierre Mac Orlan, Roger Vitrac o Jean
Cocteau, se acercan al cine desde una perspectiva con valores más ideológicos y sociales que específicamente técnicos. El interés que muestran sus escritos por el cine no se traduce en una modificación formal o estilística de sus propias obras, aun cuando en algunos casos como Mac Orlan o Cocteau los trabajos que realizan para el cine sean numerosos y significativos. La colaboración entre cine y literatura en escritores como Pierre Louÿs o Jacques Prévert se caracteriza, en este mismo sentido, por un acercamiento a la imagen que distingue las posibilidades del nuevo medio de una retórica literaria propia.

Algunos demostraron su interés por el cine de manera ocasional pero reveladora por la agudeza y el alcance de su pensamiento. Guillaume Apollinaire, siempre atento a cuanto sucedía a su alrededor, no dejó escapar la eclosión del cine sin incorporarla al bagaje de cambios cruciales para la literatura francesa del nuevo siglo, al igual que Max Jacob. La precisión y la lucidez de los comentarios de Pierre Reverdy o las afirmaciones incondicionales de los surrealistas Jacques Rigaut, Pierre Unik, Tristan Tzara, Jacques Vaché o el inclasificable Ernest Gengenbach apuntan la incidencia que lo cinematográfico tuvo en las conciencias literarias antes y después de la Primera Guerra Mundial en Francia.

Un importante número de poetas nos ha dejado el testimonio de su interés como meros espectadores interesados o deslumbrados. Desde Breton hasta André Gide o Marcel Aymé, pasando por Pierre Drieu la Rochelle, Charles Vildrac, o surrealistas como Michel Leiris, Paul Eluard, René Crevel y Louis Aragon, alejados del compromiso teórico de los primeros, sus opiniones acerca del cine están situadas en el ámbito del comentario y la reseña en revistas y periódicos, sin alcanzar no obstante la profundidad y el peso de los análisis de contemporáneos suyos y la permeabilidad hacia procedimientos cinematográficos que constamos en otras obras. Del conjunto de poetas y movimientos que se manifiestan en la primera mitad del siglo XX, son dadaístas y surrealistas el más prolijo en opinar y escribir sobre cine, aunque el que menos manifestó una influencia directa del cine en la forma de sus escritos. Los surrealistas celebraron el cine como una manifestación lúdica que, en ocasiones, se convertía en provocación, como su entusiasmo por dramones populares y series como Les Mystères de New York.

En la figura de Ricciotto Canudo descansa, sin duda, un caso excepcional de apología literaria, con la práctica y la reflexión de lo que representó el cine en las primeras décadas del siglo XX para las vanguardias. 
Fue el que con más entusiasmo acogió la imagen como recurso novísimo para todas las formas del arte hasta proclamar una literatura cinematográfica. En L'Usine aux images de 1927, Canudo lleva a cabo una reflexión donde están planteados o intuidos gran parte de los planteamientos teóricos contemporáneos, como es el caso del concepto de asociación. Escritos suyos de creación como Les Romans de foules (1913), o teóricos como Nacque al mondo un sole (saggio sul poema d'un'epoca) (1906) y Hélène, Fauste et nous, précis d'Esthétique cérébriste (1920) reflejan, en mayor o menor medida, una inquietud estética en la obra de Canudo, en donde el cine ocupó un lugar privilegiado, así como un punto de referencia revelador en el conjunto de las literaturas que desembocará en las vanguardias.

El cine descubre un mundo nuevo al articular y decirse con un lenguaje novedoso. Expresión y conocimiento están de este modo ligados a rápidas trasformaciones estéticas: "Nous avons besoin du cinéma pour créer l'art total vers lequel tous les autres, depuis toujours, ont tendu" ["Necesitamos del cine para crear el arte total hacia el que todas las otras artes han estado orientadas desde siempre"] (Canudo, 1927, p. 5), apunte enraizado en la reflexión sobre el mundo moderno. De igual modo, Jules Romains se sirve de la película Metrópolis de Lang para hacer un repaso de las cuestiones que se ven implicadas en la obra cinematográfica, fundamentalmente de carácter estético. El cine y sus implicaciones con el arte moderno ocupa un lugar importante en las reflexiones de Romains, así como la consciencia plena de la particularidad en el método visual con singulares consecuencias para el pensamiento de su época, sin determinar la medida y el alcance. Ocurre con frecuencia que las opiniones de los autores se sustentan más en la intuición del artista que piensa en su arte como protagonista: “J'ai pu m'apercevoir qu'elle tenait à la rencontre d'une certaine grandeur dans l'invention technique avec la grandeur -momentanée- de la pensée" ["He podido darme cuenta de que reflejaba el encuentro de una cierta grandeza de la invención técnica con la grandeza-momentánea-del pensamiento"] (Romains, 1977, pp. 29-30).

El protagonismo del cine en un mundo de innovaciones permanentes, y principalmente en la literatura y sus procedimientos, juega un papel decisivo en las preocupaciones literarias de la primera mitad del siglo XX. Todavía en 1929 el cine es percibido con no pocas reticencias por la norma cultural, lo que nos informa, igualmente, del carácter novedoso y vanguar- dista que un compromiso directo con el séptimo arte significaba para los poetas de principios del siglo XX. Todavía más evidente resulta la afirmación de Philippe Soupault donde espera su reinado en un futuro lo más próximo posible: “Mais le règne du cinéma n'est pas encore venu, souhaitons cependant qu'il arrive le plus tôt possible." ["Aunque el reino del cine todavía no ha llegado, esperemos no obstante que llegue lo antes posible"] (Soupault, 1979, p. 61)

Durante las primeras décadas del siglo, el cine no deja de ser un elemento todavía extraño, en la medida en que seguía siendo considerado un medio poco noble, e incomparable con el resto de las artes. Los comentarios de poetas e intelectuales reflejan, no obstante, la extensa preocupación poética por cuestiones que atañen a la creación en su estado más profundo. Aun tratándose de ensayos breves, tienen la inteligencia y la densidad necesaria para tratar con una lucidez poco comunes las principales cuestiones que atañen a la retórica de la imagen, todavía hoy vigentes. Benjamin Péret expresa, al igual que otros contemporáneos suyos, su convencimiento sobre el verdadero alcance del nuevo arte como herramienta al servicio de las conciencias creadoras del siglo incipiente. Nada como el cine despertó más esperanzas y ocasionó mayores desengaños, explica Péret, con un sentimiento de asombro "maravilloso" ante el mundo:

Jamais aucun moyen d'expression n'a engendré autant d'espoir que le cinéma. Par lui, non seulement tout est possible, mais le merveilleux lui-même est placé à portée de la main. Et cependant, jamais on n'a observé tant de disproportion entre l'immensité des possibilités, et le dérisoire des résultats.

[Jamás ningún medio de expresión ha suscitado tanta esperanza como el cine. No sólo todo lo puede, sino que lo maravilloso se sitúa al alcance de su mano. $Y$ sin embargo nunca se ha podido comprobar tanta desproporción entre sus inmensas posibilidades y sus resultados irrisorios] (Péret, 1951, pp. 7-8).

Actitud que coincide con otros escritores contemporáneos suyos que declararon también haber sido traicionados por aquello que el cinematógrafo parecía ofrecer en un principio, como Benjamin Fondane o Robert Desnos. Ninguno demostró mayor entusiasmo y decepción a un tiempo que Antonin Artaud. Vinculado con el cine desde múltiples facetas, desde actor en películas como Napoléon (1927) de Abel Gance, realizando guiones imprescindibles para la historia del cine como La Coquille et le Clergyman llevada a la pantalla por Germaine Dulac en 1927 o radical crítico siempre dispuesto a comprender las posibilidades del 
cine para encaminarlo hacia una insospechada revolución de las ideas. Buena parte de sus planteamientos teatrales hubieran encontrado soluciones formales más sencillas y eficaces en el terreno cinematográfico.

Nos parece definitivo y revelador su testimonio para encontrar numerosas respuestas a los interrogantes que plantea nuestro estudio. Aspectos como las funciones de la cámara, su discurso fragmentario, la velocidad y el tiempo, esa realidad incontestable de las imágenes y su poesía, se traducen en formas apasionadas de un desengaño (Artaud, 1951, pp. 1719), pues Artaud, que lo esperaba todo del cine, no pudo encontrar el camino propicio a sus necesidades creativas en un medio cada vez más condicionado por aspectos económicos e industriales.

Otros comentarios, más en la línea de una tendencia surrealista a la manera de Soupault, con la que estuvo relacionado de manera ocasional, tratan aspectos de las películas Animal Crakers y Monkey Business de los hermanos Marx, referencias suficientes para reservar en la obra de Artaud un espacio privilegiado al cine en todas sus facetas. Artaud subraya el valor y la confluencia de la palabra y la imagen, así como la capacidad del cine para mostrar lo que habitualmente está vedado a la visión, característica clave en la incisión intelectual de la imagen en los esquemas intelectuales de la modernidad literaria:

La libération par le moyen de l'écran d'une magie particulière que les rapports coutumiers des mots et des images ne révèlent pas /.../. Dire en quoi cette sorte de magie consiste est difficile, c'est en tout cas quelque chose qui n'est pas spécifiquement cinématographique peut-être, mais qui n'appartient pas non plus au théâtre et dont seuls certains poèmes surréalistes réussis /.../ pourraient donner une idée.

[La liberación a través de la pantalla de una magia particular que las relaciones habituales entre palabras e imágenes no revelan /.../ Decir en qué consiste esta especie de magia es difícil, es en cualquier caso algo que no es específicamente cinematográfico tal vez, pero que no pertenece tampoco al teatro y que sólo algunos poemas surrealista consiguen /.../ y podrían dar una idea] (Artaud, 1964, p. 213).

El cine no sólo descubre técnicas nuevas y propuestas para una manera de ver el mundo que en literatura encuentran un eco clave en los presupuestos surrealistas, transforma profundamente el sentimiento que existe ante ese mundo y la sensibilidad que su propia dinámica va creando al incorporar aquellos asuntos, como ocurre en Metrópolis, que tocan muy cerca desde la realidad cotidiana hasta la ficción.
Como fuente de recursos para la renovación literaria, el cine marcó la trayectoria de Blaise Cendrars. Prueba de esta presencia visual es la importante producción de textos con una intención deliberadamente cinematográfica. Además de este aspecto de la creación en Blaise Cendrars, existen en su obra numerosas reflexiones sobre el protagonismo del cine en la historia y la vida de la que es testigo. Cendrars se interesó por la imagen como vehículo de expresión con grandes posibilidades. Cendrars no sólo demuestra un conocimiento del cine en cuanto a producción de películas importantes de su época (Gance, Griffith), sino que debido a su participación activa como guionista es consciente de la técnica visual que las imágenes implican, exigiendo además una renovación de procedimientos en literatura estrechamente relacionados con criterios de montaje y primeros planos: "Fixez l'objectif sur une main, le coin de la bouche, l'oreille, et le drame se profile, s'agrandit sur un fond de mystère lumineux. Déjà on n'a plus besoin du discours; bientôt le personnage sera jugé inutile". ["Fijar el objetivo sobre una mano, la comisura de la boca, la oreja, y el drama surge, se agranda sobre un fondo de misterio luminoso. Ya no necesitamos de la palabra, y pronto también el personaje será considero innecesario"] (Cendrars, 1987, p. 36)

En este mismo sentido, Colette es consciente de la importancia de la fragmentación y del primer plano entre las posibilidades comunicativas que ofrecía el cine. "L'Outrage inaugure, en coin d'écran, une mode ingénieuse de médaillons où s'isole et vit une scène indépendante de la scène principale, synchronisme agréable, et logique en somme" ["El ultraje inaugura en una esquina de la pantalla, un modo ingenioso de medallones donde se aísla y vive una escena independiente de la escena principal, sincronismo agradable y lógico en suma"] (Colette, 1975, p. 43). Las numerosas actividades de Colette, desde la crítica, la confección de subtítulos, hasta los guiones, corroboran el apasionamiento que despertó el arte de la luz y de la sombra entre poetas, novelistas y dramaturgos de comienzo de siglo. Unos comentarios que se transforman en una evolución de lo muy literario, en sus primeros trabajos, hasta cuestiones más técnicas que surgen en sus críticas posteriores, revelan que los aspectos filosóficos y estéticos dan paso, en ocasiones, a apreciaciones de índole técnica, reflejando unos análisis sobre recursos visuales entroncados en aspectos de retórica comunes a la literatura y el cine como el aislamiento o escisión de imágenes.

De los casos más sobresalientes sobre este vínculo cine-literatura durante los comienzos de la imagen, 
destaca Benjamin Fondane. En sus trabajos queda recogida una actitud muy sensible hacia las implicaciones entre poesía e imagen, característica común a los intelectuales relacionados con el medio cinematográfico que estamos analizando. A partir de la película Entr'acte de René Clair, tiende un puente entre el director y el poeta Rimbaud (Fondane, 1984, pp. 51-54). Por otro lado, en otros trabajos analiza con precisión conceptos como expresión lingüística, implicando de esta manera el lenguaje del poema (Fondane, 1984, pp. 87-92). Fue siempre una especial preocupación para todos los autores relacionados con las imágenes, especialmente Artaud, como hemos visto, el hecho de que el cine renunciara a las extensas posibilidades que poseía y que, a juicio de poetas como Fondane, renuncia a esa calidad de innovación absoluta, a las posibilidades creadoras de un lenguaje y unas construcciones innovadoras, para caer en producciones comerciales y pobres desde el punto de vista creativo.

La característica que marca una actividad que diferencia a unos creadores de otros atiende al aprendizaje y puesta en práctica de esa retórica deducida en sus diversos análisis teóricos, como puede comprobarse en los poemas cinematográficos de Artaud, Péret, Robert Desnos o Jules Romains. La marcada influencia del cine en obras como Titanic (1937) de Benjamin Fondane o Trois scénaris. Paupières mûres-barre fixeMtasipoj. Cinépoèmes (1928), donde se descubre la intención profundamente cinematográfica del autor al calificar lo que desde cierto punto de vista puede ser considerado guión convertido en cine-poema. Otro tanto sucede en los poemas cinematográficos de Soupault (Soupault, 1925, pp. 179-182), donde la intención específica de reunir poesía y cine queda plasmada en la escritura particular de este tipo exclusivo de literatura cinematográfica, uno de los cuales inspiró a Ruttmann para realizar la desaparecida película en la que el propio Soupault participó. También Soupault intervino en guiones como Le Cœur volé para Jean Vigo, o mediante numerosas colaboraciones con escritos para revistas como Europe Nouvelle, Bravo o La Revue du cinéma. Además de su producción crítica, en los que refleja una regular recepción de las películas de su época, pone en práctica recursos de origen visual sobre los que el poeta reflexiona previamente, aun a pesar de su obstinación en defender una radical separación entre uno y otro: “On ne devrait jamais se lasser de répéter, même dans le désert, que le cinéma n'a rien à faire avec la littérature, le théâtre ou le caféconcert", reconociendo al mismo tiempo que "le cinéma triomphe: il nous dote d'un sens nouveau. II nous fait voir dans le temps et non plus seulement dans l'espace. Nous découvrons de nouveaux rythmes, de nouveaux gestes et ces répétitions éternelles de la nature." ["Nunca deberíamos cansarnos de repetir, incluso en el mismo desierto, que el cine nada tiene que ver con la literatura, el teatro o el café-concierto (...) El cine triunfa: nos dota de un sentido nuevo. Nos hace ver en el tiempo y no sólo en el espacio. Descubrimos nuevos ritmos, nuevos gestos y las repeticiones eternas de la naturaleza"] (Soupault, 1979, p. 65).

Georges Ribemont-Dessaignes descubre esa dimensión estrictamente cinematográfica por la cual las imágenes revelan los signos de lo animado en lo inanimado y viceversa, del mismo modo que lo hará Tristan Tzara en otro momento. La manipulación de lo visual y, más que de ningún otro elemento, del tiempo, son los puntos cardinales en las inquietudes del arte y la literatura de principios de siglo. Sirviéndose de la expresiva imagen de "terminar con la burocracia del espíritu y el ojo" Ribemont-Dessaignes muestra la incidencia extraordinaria del procedimiento cinematográfico en la concepción profunda del mundo y, por consiguiente, de su expresión ulterior. Se trata de aspectos claves en la comprensión de las transformaciones radicales que sufre la retórica literaria francesa al iniciarse el siglo. La modificación del espacio y el tiempo constituyen igualmente una de las principales cuestiones estéticas en los trabajos del poeta Benjamin Fondane, así como en cualquier ensayo a los que estamos aludiendo donde la pregunta principal sobre el cine está encaminada hacia la cuestión formal y de procedimientos.

Fondane realiza un acertado análisis sobre las transformaciones de la técnica cinematográfica con la llegada del sonido (Fondane, 1930, pp. 137-150). Sus trabajos acusan la utilización real de procedimientos de origen visual que poseía Fondane, reflejados en la colaboración y realización de películas como Tararira, trabajo hoy perdido. Tanto sus estudios como los films realizados o sus guiones cinematográficos, prueban la presencia de las cuestiones relacionadas con la imagen y sus consecuencias en la creación literaria entre las privilegiadas actividades del poeta. No debemos olvidar, en cualquier caso, que los propios escritores tuvieron presente en todo momento la exclusividad irreductible de cada uno de los lenguajes, el literario y el cinematográfico, así como la razón de ser del segundo y sus extraordinarias innovaciones.

Muchos poetas se manifestaron reacios a reconocer los intercambios entre ambas disciplinas. Trataron de fijar los límites entre uno y otro que salvaguardaran el enriquecimiento mutuo, aun cuando concretizaran en 
su poesía recursos extraídos del ámbito visual. Georges Ribemont-Dessaignes realiza una puesta a punto del apelativo surrealista para desmitificar la habitual facilidad de atribuir cualidades surrealistas en manifestaciones diversas muy lejos de la estética surreal. Para Ribemont-Dessaignes el séptimo arte acusa también una influencia directa de determinados planteamientos poéticos, y revela esa importante cualidad por la que la esencia misma de lo visual puede hacer verosímil, dado su incuestionable realismo, o lo que Bazin en su "Ontología de la imagen cinematográfica" describía como la aceptación de la imagen como discurso verdadero, por increíble que pudiera parecer en pantalla:

Il porte la marque de l'évolution de la sensibilité poétique, non pas tant dans son apparence formelle, démesurée réaliste, qui pourtant lui assure toutes les possibilités, grâces aux magies de la technique, que dans l'apparition sur l'écran des secrets que l'être humain cache jalousement. (Ribemont-Dessaignes, 1976, p. 295).

Robert Desnos, junto a Ribemont-Dessaignes, forma parte de ese grupo de poetas estrechamente relacionados con el mundo de las imágenes, como pueden serlo Soupault o Fondane, aunque lejos de conseguir las realizaciones de Cocteau, que participó intensamente en el análisis lírico y la práctica cinematográfica. No hay que olvidar sin embargo que el poema desparecido de Desnos La Liberté ou l'amour sirvió como punto de partida a una de las producciones clave del cine experimental. La película L'Etoile de mer (1929), de Man Ray y Robert Desnos, por lo tanto, refleja el carácter de la actividad cinematográfica del poeta. A los numerosos comentarios críticos sobre películas, se suman sinopsis y guiones cinematográficos de un valor inestimable. La significativa producción del poeta sobre y para el cine, confieren un valor incomparable a la hora de investigar de qué forma la aparición del cinematógrafo en el panorama literario de principios de siglo pudo cambiar las directrices de la retórica para la literatura en general y la poesía en particular que sentó las bases retóricas de los grandes cambios literarios contemporáneos.

Al referirnos a teoría de las ideas estamos aludiendo a una actitud intelectual que la mayoría de los poetas de la vanguardia mantuvo con respecto al fenómeno cinematográfico en el dominio de las humanidades. A este grupo pertenecen aquellos que, interesados ampliamente por la imagen, vieron en el cine, además de componentes lingüísticos, factores que han impulsado cambios sociales, ideológicos y estéticos, en un sentido más amplio y general que el estrictamente lingüístico.

Intelectuales como Maurois, Mac Orlan y Jean Cocteau, reflejan en sus trabajos una actitud analítica que recorre cuestiones que van desde una concepción filosófica de la poesía, entendida como un estadio superior al que debe tender el cine, como es el caso de André Maurois, hasta un tratamiento especialmente contemporáneo de lo imaginario por Mac Orlan, entendiendo el cine como fuente de sueño, no en el sentido surrealista del término, sino hacia su capacidad para generar historias, imaginación, sin olvidar tampoco el especial planteamiento de Cocteau como expresión también poética, en el sentido más espiritual del término.

André Maurois pone de manifiesto los estrechos lazos entre medios diversos, subrayando las cualidades poéticas del cinematógrafo y reivindicando de forma decidida su cualidad de arte, lo cual no era de ningún modo evidente durante los primeros tiempos cuando frecuentemente se le negaba ese privilegio. Demuestra ser un gran conocedor, aportando sus opiniones sobre la obra de Charles Chaplin, aunque alejado de los intereses surrealistas por las películas de Charlot. Realiza un repaso de la historia y, ocasionalmente, la utilización de sus técnicas, e inserta fragmentos de películas en lo que en origen se trató de una conferencia. Reivindica la capacidad expresiva de las imágenes frente a la palabra y hace hincapié sobre puntos esenciales, como el valor de los primeros planos, subrayando la intensidad y la vida de los objetos a nuestro alrededor. Desde su condición de escritor, André Maurois anuncia el progresivo valor que las imágenes toman en nuestras vidas y la importancia incomparable que ha alcanzado en la vida intelectual y estética:

Donc, non seulement un art peut prendre comme matière les images en mouvement mais, en le faisant, il nous enseigne à voir un univers nouveau et nous aide à éliminer doucement ce qu'il pouvait avoir de trop verbal dans notre civilisation. Sans doute une longue éducation nous rendra-t-elle en partie le pouvoir d'observation du primitif.

[No sólo un arte puede tomar las imágenes en movimiento, sino que haciéndolo nos enseña a ver un universo nuevo y nos ayuda a eliminar dulcemente lo que de verbal podría haber de más en nuestra civilización. Sin duda una larga educación nos permitirá recuperar en parte un primitivo poder de observación] (Maurois, 1927, pp. 23-24).

Determinados escritores como Maurois se acercaron al cine desde la distancia del comentario, no exen- 
to de interés y apasionamiento, o desde la inmediatez del que no sólo reflexiona, sino que se propone realizarlo. El novelista Pierre Mac Orlan participó en numerosos films como guionista o colaborador, entre los que destaca su trabajo en el guión de L'Inhumaine (1924) de Marcel L'herbier, o en la película Le Chant de l'équipage, nunca realizada, así como sus comentarios en Les Petits métiers de Paris (1932) de Pierre Chenal y Fêtes foraines (1933) de J. Arnaud.

La noción de lo "fantástico", apuntada más atrás por Georges Ribemont-Dessaignes, vuelve a hacer acto de presencia en los escritos de Mac Orlan señalando uno de los impactos mayores que la técnica visual desarrolló entre los intelectuales, la capacidad de la imagen para mostrar lo que estaba oculto a la visión mediante procedimientos mecánicos:

Le cinéma, en une seconde, par un procédé d'accélération des images, produit de tels miracles. Je songe, en ce moment, à cette extraordinaire évolution d'une graine de haricot qui cherche à tâtons, mais comme une aveugle diligeante, le tuteur qui l'attend.

[El cine, en un segundo, por un procedimiento de aceleración, produce tales milagros. Pienso en estos momentos en la extraordinaria evolución de un grano de judía que busca a tientas, como una ciega diletante, el tutor que la espera] (Mac Orlan, 1928, pp. 9-10).

Incluye en sus trabajos una serie de apreciaciones valiosísimas en torno a aquello que el cine tiene de revolucionario e incomparable, fundamentalmente en lo referente a su capacidad fabuladora. Mac Orlan trata algunos de los aspectos relacionados con las trasformaciones intelectuales y cierta actitud ante la realidad del mundo que sufren irreversibles cambios a raíz de la incidencia del cine en coordenadas contemporáneas, como su capacidad para mostrar una semilla germinando a gran velocidad, lo cual ha de modificar inevitablemente la noción de tiempo en el espectador, o las exigencias del montaje cinematográfico en la capacidad interpretativa del público.

Aunque sin duda el ejemplo más característico de esta incorporación de la imagen a planteamientos generales estéticos sea el de Jean Cocteau. Si bien sus planteamientos artísticos están muy lejos del atormentado mundo de Artaud, Cocteau, desde sus guiones y películas, como Le Sang d'un poète, Les Enfants terribles, La Belle et la bête, o Le Testament d'Orphée, ponen irremediablemente en relación la práctica literaria y cinematográfica.

En sus escritos descubrimos la dimensión extremadamente literaria que Cocteau propone como interpretación de la imagen, considerada como un medio de producción poética. Esta preocupación por la existencia de una dimensión lírica es muy característica de cierto momento en intelectuales y críticos que se aproxima más hacia el final del período surrealista, antes de la Segunda Guerra Mundial. A lo largo de sus entrevistas, Cocteau responde principalmente a cuestiones relacionadas con su propia producción cinematográfica y este planteamiento particular que lo caracteriza en los lazos que establece entre pulsión poética y resultados cinematográficos. Del conjunto de escritores que hemos detallado, Jean Cocteau es aquél que ha desarrollado mayor actividad real, convertida en numerosos films, a diferencia de otros escritores contemporáneos cuyos guiones quedaron reducidos a la posibilidad irrealizable del proyecto.

Otros ensayos desarrollan aspectos relacionados con la aparición de una sociedad que comienza a gestar nuevos valores y rasgos característicos de un modo de vida ligado a la imagen como forma de expresión. El cine se revela como vehículo de reflexión política, manipulación o destrucción de valores clásicos en el arte, del que rompe el habitual elitismo utilizado como salvaguarda al convertirse en el espectáculo de masas por excelencia. En este sentido, si bien las opiniones de Georges Duhamel son negativas, e incluso podríamos decir que realiza su cruzada particular contra lo que la aparición del cine representa, resultan extremadamente significativos sus comentarios, los cuales revelan, precisamente, todo el interés formal y técnico que despierta en los artistas. Y es precisamente el hecho de poner de relieve esos aspectos, lo que confiere al texto de Georges Duhamel una información de gran ayuda para la comprensión de cómo el espectáculo visual era recibido:

Elles passent, c'est le mot. Alors que toute œuvre digne de ce nom cherche à demeurer, elles passent, ces images qui ne représentent pas la vie, mais un monde à part, le monde-cinéma, où tout est faux, arbritaire, absurde. Les images dont une quelconque, isolée, immobile, apparaît, par son échelle, ses dimensions, sa mise en page, ses trucs, ses conventions, ses poncifs /.../ comme prodigieusement étrangère à ce que nous savons de la vie véritable et vivante. ${ }^{1}$

[Pasan, esa es la palabra. Mientras que toda obra digna de ese nombre persigue perdurar, pasan, esas imágenes que no representan a la vida sino un mundo aparte, el mundo-cine, donde todo es falso, arbitrario, absurdo. Una cualquiera de esas imágenes, aislada, inmóvil, aparece debido a sus proporciones, sus dimensiones, su puesta en página, sus trucos, sus convenciones, sus falsedades /.../ como prodigiosamente ajena a lo que entendemos por vida viva y verdadera] (Duhamel, 1930, p. 57). 
Ya la inclusión de un apartado dedicado al cine en un libro que se propone tratar aspectos que tratan de adivinar el futuro, muestra la importancia que las imágenes van cobrando en la actualidad intelectual de la época.

El cine refleja y descubre el valor de lo inmediato, de esa realidad instantánea del presente. En el interesante estudio citado al comienzo de este trabajo, Léon-Paul Fargue se pregunta, precisamente, sobre aspectos de la actualidad, junto a los deportes y las grandes finanzas. Su trabajo consiste en una reflexión que recoge desde recuerdos hasta temas candentes, lo que nos informa de la notable importancia que al desarrollo del cinematógrafo se le está concediendo. Su estudio sobre la imagen en particular refleja un análisis sobre el cine desde sus comienzos, observando en la evolución de sus técnicas un aparato creador que ofrece numerosas posibilidades en el dominio de la creación.

El erotismo y la imagen se convierte también en objeto de reflexión. El trabajo más sobresaliente de André Salmon consiste en un ensayo publicado en 1932 sobre Marlène Dietrich, musa del erotismo en los años treinta, en el que podemos encontrar un extenso comentario de su filmografía. Repara, igualmente, en sucintas referencias a las técnicas cinematográficas, muy útiles para entender el modo en que estos procedimientos alcanzaban la sensibilidad estética del receptor experimentado en otras actividades, dato fundamental si deseamos trazar un esquema de las posibles incidencias de la retórica visual en los mecanismos literarios.

Las imágenes transportan los grandes temas de la época inaugurando así lo que ha de convertirse en la gran comunicación de masas del presente. Mac Orlan habla en un prólogo sobre el personaje principal del film y de la novela titulado "A Propos de Karen", en el que volvemos a encontrarnos con el elemento popular como clave para la comprensión del cine como espectáculo de masas que atañe a una extensa sensibilidad que remonta a los principios mismos del origen de la emoción humana. Esta vulgarización será en principio un inconveniente con respecto a su consideración como arte por derecho pleno, considerado en sus inicios más como atracción de feria que como manifestación artística propiamente dicha. Por el contrario, esta misma amplificación insospechada de la superficie de receptores, confiere al cinematógrafo una cualidad que hará llegar sus transformaciones a todos los sectores sociales acudiendo a la mutación misma de valores arraigados en la vida, entendida en la actualidad necesariamente vinculada con la imagen.
En otras ocasiones se trata de sus experiencias propias como fuente de análisis desde la inmediatez del contacto más que del análisis intelectual, lo que facilita, igualmente, como Paul Morand, llevar a la ficción el mundo y el ambiente cinematográfico desde una perspectiva absolutamente imaginaria. El relato de su propia experiencia en Estados Unidos y su contacto personal con este ambiente, y en particular con Chaplin. La relación de Morand no se limita a una aportación desde la distancia del comentario, sino que va mucho más allá. Todo ello le conduce a publicar en 1934 la novela France la doulce inspirada en este contexto, desde una ironía verbal que pone de manifiesto los entresijos del mundo del cine, con sus pequeñeces y sus grandezas.

Qué duda cabe que el cine deslumbró y supuso punto de inflexión en el desarrollo de las formas y recurso expresivos de la literatura y del arte del siglo XX. Los testimonios analizados reflejan hasta qué punto la presencia del cine se fue extendiendo en los sectores intelectuales hasta impregnar su totalidad, atrayendo hacia la magia de la luz a creadores de disciplinas diversas. En mayor o menor medida, la crítica temática presente en la mayoría de los autores, marca el grado de interés que incorporó a la vida cultural parisina hasta el estallido de la Segunda Guerra Mundial. Cuesta trabajo imaginar hoy, con nuestras competencias visuales perfectamente asentadas, las dificultades, intereses y sorpresa que estos primeros espectadores del cine experimentaron ante la irrupción de un lenguaje nuevo que articulaba narraciones mediante imágenes. Tanto intelectuales como escritores, como el público en general, tuvo que aprender a descifrar las claves de esta nueva gramática al mismo tiempo que la propia gramática se inventaba a sí misma. Podemos hacernos una idea a través de sus testimonios, dudas, celebraciones y reproches, de las expectativas que este nuevo arte despertó entre los creadores de principios de siglo XX. El impacto del cine fue enorme, transformando el panorama de la literatura entonces hasta la fecha.

Esto nos lleva a reflexionar sobre la cuestión de la influencia del cine en la literatura. Sin duda las nuevas técnicas cinematográficas, fundamentalmente el montaje como recurso narrativo, y sus consecuencias como la elipsis, la metonimia visual o el primer plano, significaron una innovación importante en el abanico de herramientas expresivas que ven la luz desde finales del siglo XIX. Coincidimos con José Antonio Pérez Bowie cuando señala que "el discurso poético del cine como discurso, y la del discurso cinematográfico como 
vehículo se presenta como un fenómeno de múltiples dimensiones que no depende exclusivamente de las propiedades empíricas de un objeto, el filme [...] sino que se instaura en el espacio social de la comunicación constituyendo dentro de él un área muy bien interrelacionada con las demás y, de igual modo, se crea en el ámbito de los diferentes grandes géneros del discurso, icónicos y no icónicos" (Pérez Bowie, 2008, p. 30). Efectivamente, más que de influencia directa del cine sobre la literatura, pensamos que el estudio de la interacción de lenguajes diversos como el visual y el verbal ha de plantearse como respuesta específica y equivalente a unas necesidades comunicativas comunes. Como señalábamos en los primeros párrafos de este trabajo, la imagen como procedimiento asocia- tivo es un recurso que comparten literatura, pintura y cine. La imagen poética, el papier collé o el collage, así como el montaje cinematográfico, son expresiones de una misma necesidad expresiva. El cine, y su recepción en los otros órdenes artísticos de comienzos de siglo XX, es el indicio de las transformaciones profundas que el arte está experimentando y que se remontan, desde un punto de vista estético, a los planteamientos creativos que se fraguan en las últimas décadas del siglo precedente. De este modo, podemos concluir afirmando que los intelectuales que asistieron al nacimiento del séptimo arte estaban ya preparados para recibir y comprender el cine, que se manifiesta como el síntoma y no el origen de la estética visual de la modernidad.

\section{BIBLIOGRAFÍA}

Artaud, A. (1932). Les frères Marx. La Nouvelle Revue Française, 220.

Artaud, A. (1951). La vieillesse précoce du cinéma. L'Age du cinéma, 2.

Artaud, A. (1970). CEuvres complètes. Paris: Gallimard.

Bazin, A. (1985). Qu'est-ce que le cinéma?. Paris: Editions du Cerf.

Breton, André (1985). Manifestes du surréalisme. Paris: Gallimard.

Canudo, R. (1906). Nacque al mondo un sole (saggio sul poema d'un'epoca). $\mathrm{Pa}$ ris: Società Dante Aligieri.

Canudo, R. (1920). Hélène, Fauste et nous, précis d'Esthétique cérébriste. Paris: $\mathrm{R}$. Chiberre.

Canudo, R. (1923). Les Romans de foules. Les transplantés (La ville visage du monde). Paris: Fasquel.

Canudo, R. (1927). L'Usine aux images. Genève: Office Central d'Edition.

Cendrars, B. (1987). Aujourd'hui 19171929. Paris: Denoël.

Cocteau, J. (1973). Du Cinématographe. Paris: Pierre Belfond.

Cocteau, J. (1985). Entretiens sur le cinématographe. Paris: Pierre Belfond.

Colette (1975). Colette au cinéma, chroniques, dialogues, scénarios. Paris: Flammarion.
Crary, J. (1990). Techniques of the Observer. On Vision and Modernity in the Ninteenth Century. Cambridge, London: MIT Press.

Desnos, R. (1966). Cinéma. Paris: Gallimard.

Desnos, R. (1979). Nouvelles Hébrides et autres textes 1922-1930. Paris: Gallimard.

Duhamel, G. (1930). Scènes de la vie future. Paris: Mercure de France.

Eisenstein, S. (1986). The Film Sense. London: Faber \& Faber.

Fargue, L. P. (1944). Lanterne magique. Paris: Robert Laffont.

Fondane, B. (1928). Trois scénaris. Paupières mûres-barre fixe-Mtasipoj. Ciné poèmes. Paris: Documents de l'esprit nouveau.

Fondane, B. (1930). Du muet au parlant: grandeur et décadence du cinéma. Biffure, 5.

Fondane, B. (1937). Titanic. Bruxelles: Les Cahiers du Journal des poètes.

Fondane, B. (1984). Ecrits pour le cinéma. Le muet et le parlant. Paris: Plasma.

Jacob, M. (1987). Art poétique. Paris: L'Eloquent.

L'Herbier, M. (1946). Intelligence du cinématographe. Paris: Editions Corrêa.
Lacassin, F. (ed.) (1982). Pierre Mac Orlan et le cinéma. Reims: Maison de la Culture André Malraux.

Lautréamont (1953). Ouvres complètes. Paris: José Corti.

Mac Orlan, P. (1928). La petite marchande d'allumettes. Paris: Gallimard.

Maurois, A. (1927). La poésie du cinéma. En L'Art cinématographique, III. Paris: Félix Alcan.

Morand, P. (1928). Au sujet de Chang (le journal de la jungle siamoise). Paris: Gallimard.

Morand, P. (1934). France la douce. Paris: Gallimard.

Péret, B. (1951). Contre le cinéma commercial. L'Age du cinéma, 1.

Pérez Bowie, J. A. (2008). La teoría literaria en la teoría cinematográfica. Salamanca: Ediciones Universidad de Salamanca.

Poulaille, H. (1927). Charles Chaplin. Paris: Grasset.

Puyal, A. (2003). Cinema y arte nuevo: la recepción fílmica en la vanguardia española (1917-1939). Madrid: Biblioteca Nueva.

Reverdy, P. (1975). Nord-Sud, Self Defence et autres écrits sur l'art et la poésie (1917-1926). Paris: Flammarion. 
Ribemont-Dessaignes, G. (1946). Printemps, surréalisme et cinéma, L'Ecran français, 45.

Romains, J. (1977). Métropolis vu par Jules Romains. Avant-Scène (Les écrivains français devant le cinéma 1928-1929), 197.

Salmon, A. (1932). Marlène Dietrich. Paris: La Nouvelle Librairie Française.
Soupault, Ph. (1925). Poèmes cinématographiques. Cahiers du mois, 16/17.

Soupault, Ph. (1931). Charlot. Paris: Plon.

Soupault, Ph. (1979). Ecrits de cinéma 1918-1931. Paris: Plon.

Urrutia, J. (2002). Federico García Lorca, Luis Buñuel y Jean Espein, de la poesía al cine. El Extramundi y los Papeles de Iria Flavia, 31.
Utrera Macías, R. (2006). Poética cinematográfica de Rafael Alberti. Sevilla: Fundación El Monte.

Virmaux, O. y Virmaux, A. (eds.). (1979). La Revue du cinéma 1928-1931, 19461949. Paris: Pierre Lherminier Editeur. 